\title{
Music therapy as a therapeutic tool in improving the social skills of autistic children
}

\author{
Geetha Bharathi, Anila Venugopal and Balachandar Vellingiri ${ }^{*}$
}

\begin{abstract}
Background: The Cochrane Collection reviews of randomized clinical trials (RCT) showed a favorable result of music therapy (MT) on individuals with autism spectrum disorder (ASD) compared with a placebo treatment.

Objective: This study focuses on accessing whether MT can improve the development of social skills of autistic children and to check if the effects of MT are long lasting.

Materials and methods: This study was designed as a pre-test/post-test and follow-up among the autistic children. Fifty-four children with mild to severe autism were selected and assigned into two groups: active and passive. The children received MT for 3 months and the groups were followed-up for 3 months. The data were analyzed with IBM-SPSS-21 software using $t$ test and the groups were compared by analysis of covariance.

Results: The results of the MT intervention were mostly apparent in the following subscales - understanding/ perspective-taking, initiating interactions, responding initiation, and maintaining interactions with others. The post-test covariance analysis results showed a significant increase in social skills' scores $(p<0.05)$. Also, the $t$ test results of the paired-sample revealed that the effectiveness of MT has been continual during the followup phase.
\end{abstract}

Conclusions: The study illustrated that MT is an effective intervention in improving social skills of autistic children with steady effects. MT helped in developing a form of communication for these children which led to an improvement in their ability to understand, respond, and maintain their interaction with their peers.

Keywords: Autism, Music therapy, DSM-5, Social skills, Orff-Schulwerk

\section{Introduction}

Autism spectrum disorders (ASD), including autism, denotes a group of neurodevelopmental disorders with social interaction, verbal, and nonverbal communication difficulties in different levels and monotonous behaviors [1]. The world-wide prevalence of autism is reported to be $1-3 \%$. Autism has an adverse effect on the brain's normal social and communication ability with symptoms showing in the initial three years of life causing individuals affected with ASD to be subjected to peer refusal and social seclusion. It has been shown that social and

\footnotetext{
*Correspondence: geneticbala@yahoo.co.in; geneticbala@buc.edu.in Human Molecular Cytogenetics and Stem Cell Laboratory, Department of Human Genetics and Molecular Biology, Bharathiar University, Coimbatore, Tamil Nadu 641 046, India
}

communication deficits may impact academic performance, occupational accomplishment, and mood/anxiety setbacks, which demands an early intervention to counterbalance the potential risk factors that could impact their social competence and cognitive problem-solving proficiencies.

Music therapy (MT) is a time-honored health profession in which music is used within a therapeutic association and deals with physical, emotional, cognitive, and social requirements of an individual. Music is a form of human communication and can address problems of movement, sensing, and feeling. A musical response is possible for a child who has severe physical, intellectual, or emotional handicap [2]. Orff Schulwerk approached MT from music developed by German composer Carl 
Table 1 Total social skill rating in active intervention and passive group of ASD children

\begin{tabular}{|c|c|c|c|c|}
\hline Group & Test & No & Mean & SD \\
\hline \multirow[t]{3}{*}{ Intervention active group } & Pre-test & 26 & 74.08 & 7.39 \\
\hline & Post-test & 26 & 114.85 & 15.07 \\
\hline & Follow-up & 26 & 82.46 & 18.73 \\
\hline \multirow[t]{3}{*}{ Control passive group } & Pre-test & 26 & 72.31 & 7.30 \\
\hline & Post-test & 26 & 112.62 & 15.27 \\
\hline & Follow-up & 26 & 78.73 & 14.99 \\
\hline
\end{tabular}

Using childhood autism rating scale (CARS), 54 children with mild to severe autism were selected through convenience sampling and assigned into two groups: active and passive MT groups. Both the intervention group consisted of 26 children. Social skills of both groups were measured and recorded with the help of Triad Social Skill rating system scale

Orff (1895-1982) and Gunild Keetman. The Orff teaching method is a "child-centered way of learning". Music education involves singing, body percussion, playing on a variety of both tuned and untuned music devices, movement and dancing, and communication activities to help children with developmental delays and disabilities.

A recent review regarding monogenic diseases in India has mentioned ASD as one of the frequently occurring disorders in Indian population [3]. Based on previous studies, there is a possibility that MT can be used in a wide variety of disorders [4]. The prime idea of using music interventions was to improve non-musical abilities such as communication, social and academic standards among individuals with ASD [5]. The Cochrane Collection reviews of randomized clinical trials (RCT) showed evidence about the positive effect of MT on ASD and emphasized about the possibility of MT to increase social adaptation skills in children with ASD and to promoting the quality of parent-child relationships [6-8]. An early study by Stevens and Clark used a pre- test/post-test method to examine the social effects of a MT intervention on five boys with autism between the ages of 5 and 7 [9]. Results indicated that all five boys demonstrated significant improvements on all three subscales of Ruttenberg's autism scale [10], which includes (1) the nature and degree of relationship to an adult as a person, (2) communication, and (3) drive for mastery. The Cochrane reviewed ten studies and analyzed the short- and medium-term effect of MT interventions (1 week to 7 months) for ASD children and presented that MT intervention can rectify the major issues among ASD children $[11,12]$.

MT has shown to be of benefit to various aspects of ASD. To the best of our knowledge, this is the first kind of study to be carried out in South India. The research work done here was to analyze the impact of MT intervention in improving social communicative and responsiveness skills in ASD children. A comparative study was also done using passive and active MT and the effect of MT post the test period was studied.

Table 2 Effect of MT on social skills rating

\begin{tabular}{|c|c|c|}
\hline Social skills & Pretest: mean (SD) & Posttest: mean (SD) \\
\hline \multicolumn{3}{|c|}{ Understanding/perspective taking ability } \\
\hline Active intervention group & $15.54(3.36)$ & $2154(6.56)$ \\
\hline Passive control group & $12.77(2.54)$ & $18.85(5.34)$ \\
\hline \multicolumn{3}{|l|}{ Initiates interaction } \\
\hline Active intervention group & $25.12(6.03)$ & $30.65(4.08)$ \\
\hline Passive control group & $20.00(2.99)$ & $27.27(3.39)$ \\
\hline \multicolumn{3}{|l|}{ Responds to others } \\
\hline Active intervention group & $9.85(2.33)$ & $11.81(3.66)$ \\
\hline Passive control group & $8.62(2.70)$ & $8.42(3.08)$ \\
\hline \multicolumn{3}{|l|}{ Maintains interaction } \\
\hline Active intervention group & $21.54(3.22)$ & $24.62(5.81)$ \\
\hline Passive control group & $19.38(2.70)$ & $21.69(3.52)$ \\
\hline
\end{tabular}

The mean and SD for the four areas of social skill rating shows an improvement which is significantly greater for active group when compared to passive group during the post-test phase 
Table 3 Analysis of covariance result of total social skill assessment in two intervention groups

\begin{tabular}{lllllll}
\hline Source & Sum of squares & $\mathrm{df}$ & Mean square & $F$ & Significance & Partial eta squared \\
\hline Pre-test & 132.214 & 1 & 132.214 & 1.287 & 0.262 & 0.000 \\
Group & 1973.079 & 1 & 1973.079 & 19.212 & 0.000 & 0.215 \\
Error & 5032.248 & 49 & 102.699 & & & \\
Total & $354,116.000$ & 52 & & & & \\
\hline
\end{tabular}

With pre-test data as covariates, this table shows the analysis of total social skill assessment between the two groups. There is a significant increase in social skill among the active group when compared to passive group

\section{Materials and methods}

This study used a quasi-experimental research design with a control group and a pre and post follow-up test. The population of this study was recruited from Coimbatore city which is located at the coordinates $11.0168^{\circ}$ N, $76.9558^{\circ} \mathrm{E}$ in Tamil Nadu State, India. Sixty children (30 boys and 30 girls) from ages $6-12$ years were chosen through a convenience sampling method. They were classified as mild (30 children: 15 boys, 15 girls), moderate ( 24 children: 12 boys 12 girls), severe ( 6 children: 3 boys, 3 girls) based on DSM-5. Due to various reasons, eight children were excluded from the study and 52 children were included in the intervention group. The inclusion criteria for the study include children aged between 6 and 12 years, and mild, moderate to severe ASD as per Childhood Autism Rating Scale (CARS) scale. The exclusion criteria are as follows: the children should have had no defects like deafness, visually challenged, motor and speech difficulties, as well as should not have been under any medication. Non-compliance with the study protocol, patients diagnosed with diseases, or using psychotropic drugs were excluded from the sample. Children who took part in the study were evaluated in detail by two child psychiatrists, two occupational therapists, a pediatrician, and autism diagnosis were confirmed as per DSM-5 criteria.

For each child, pre- and post-therapy CARS score was taken by the researcher. To identify the difficulties faced by the children in the following domains-limitations in language, verbal communication, social communication, and behavioral issues, a structured interview was conducted in the first meet with the parents/care giver. Information on MT, the aim of the study, and its method was disclosed to the parents of the children. Parent's approval was obtained and consent to participate in the study was duly signed by the parents/care givers. The present study was approved by the Hospital Ethical Board.

The TRIAD Special Skills Assessment (TSSA) is a criterion-based tool which provides more specific assessment considering parent, teacher, and direct interaction with the children. The TSSA was carried out thriceprior to the intervention, following the last session of the intervention and 3 months after the intervention to analyze any behavior as problematic along with several open-ended questions to identify the child's social interests and behaviors. In this present study, the following four subsets of questions were studied: understanding/ perspective taking, initiating interactions, responding to initiations, and maintaining interactions.

In order to test our hypothesis, we designed a pre-test, post-test, and follow-up study for ASD children who received music therapy for 3 months. Social skills of the children of both groups were measured and recorded before starting the intervention using TSSA as the pretest. The study group was stratified further into two groups as active MT and passive MT intervention group. The active group was involved in singing, dancing, and playing with the musical instruments while listening to the music, whereas the passive group received MT without any interaction and listened to music alone. The active group and passive group included 26 children with 13 boys and 13 girls each.

The selected children understood the local language and 15 songs were selected accordingly. Three musical teachers were asked to rate each of them on a scale of

Table 4 Result for understanding/perspective taking assessment between the two intervention groups

\begin{tabular}{lllllll}
\hline Source & Sum of squares & $\mathrm{df}$ & Mean square & $F$ & Significance & Partial eta squared \\
\hline Pre-test & 401.047 & 1 & 401.047 & 6.976 & 0.01 & 0.125 \\
Group & 327.790 & 1 & 327.790 & 5.702 & 0.02 & 0.104 \\
Error & 2816.799 & 49 & 57.486 & & & \\
Total & $21,200.000$ & 52 & & & &
\end{tabular}

With pre-test data as covariates, this table shows the analysis of understanding/perspective taking assessment between the two groups. There is a significant increase in this ability among the active group when compared to passive group 
Table 5 Result for ability to initiate interactions with others between the two intervention groups

\begin{tabular}{lllllll}
\hline Source & Sum of squares & df & Mean square & $F$ & Significance & Partial eta squared \\
\hline Pre-test & 308.386 & 1 & 308.386 & 5.194 & 0.03 & 0.096 \\
Group & 40.529 & 1 & 40.529 & 0.683 & 0.41 & 0.014 \\
Error & 2909.460 & 49 & 59.377 & & & \\
Total & $21,200.000$ & 52 & & & & \\
\hline
\end{tabular}

With pre-test data as covariates, this table shows the analysis of initiating social interactions with others assessment between the two groups. There is no significant increase in this ability among the active group when compared to passive group

low pitch (1-3), moderate (4-6), and high (7-9). Four songs which listed the highest average scores were selected. Each song was played using a CD player for $6 \mathrm{~min}$. The first song was based on a religious theme, second was an instrumental soft piano music, the third song was a local folk song which had high tempo and pitch, and the last one was a western pop music. After playing the songs, the group was observed in silence for $10 \mathrm{~min}$. Each session lasted for $35 \mathrm{~min}$ and three sessions were carried out in a week for both the groups. The post-test social skills of both groups were measured on the fifth day and after the 3 months follow-up period, the consistency of social skills was assessed with the help of parents to explore the effect of MT.

\section{Statistical design}

Analysis of covariance (ANCOVA) along with descriptive statistics was used as the statistical technique on SPSS and dependent sample $t$ test. The level of significance was set at $p=0.05$.

\section{Result}

The mean age for the children included in the study was $9.5 \pm 2.27$. Table 1 indicated the mean of total social skill ratings and the results of the TSSA scale for the two study groups. The table showed an improvement in the social skills of the active intervention group during the post-test phase. It was significantly greater than the children of the passive intervention group. Not much difference was noted between post-test and follow-up scores in both groups. To conclude the statistical significance in social skills ratings, further analysis was employed, considering the pre-test scores as covariates of analysis.
Table 2 revealed the mean of the four areas of social skill rating for the two study groups and Table 3 showed a significant increase of total social skill ability among the active group compared with the passive MT intervention group $(p<0.05)$.

Table 4 indicated that with pre-test data as covariate, understanding/perspective taking capability improved among the active intervention group compared with the passive group $(p<0.05)$ after the MT intervention. The results in Table 5 show that when the pre-test data were considered as covariates, the ability of the active group to initiate social interactions did not show statistical significance compared with the passive group $(p>0.05)$. In contrast, the results in Table 6 show that with pre-test data as covariate, the ability of the active group to respond to others increased relative to the passive group $(p<0.05)$. The results in Table 7 also show that with pre-test data as covariate, the ability of the intervention group to maintain interactions with others significantly increased relative to the passive group $(p>0.05)$.

In Table 8, the $t$ test analysis showed no significant difference between the mean scores of social skills in posttest and follow-up which expressed that the effectiveness of MT has been consistent among the active intervention group up to the follow-up period of 3 months after the intervention.

\section{Discussion}

MT has shown to improve non-musical abilities such as communication, social, and academic standards among individuals with ASD. Numerous studies have shown that MT intervention plays a significant role in developing children's social skills significantly [13-17]. Children

Table 6 Result for ability to respond to others between the two intervention groups

\begin{tabular}{lllllll}
\hline Source & Sum of squares & $\mathrm{df}$ & Mean square & $F$ & Significance & Partial eta squared \\
\hline Pre-test & 18.338 & 1 & 18.338 & 5.699 & 0.02 & 0.104 \\
Group & 194.688 & 1 & 194.688 & 60.507 & 0.01 & 0.553 \\
Error & 157.662 & 49 & 3.218 & & & \\
Total & 4352.000 & 52 & & & &
\end{tabular}

With pre-test data as covariates, this table shows the analysis of ability to respond to others assessment between the two groups. There is a significant increase in this ability among the active group when compared to passive group 
Table 7 Result for ability to maintain interactions with others between the two intervention groups

\begin{tabular}{lllllll}
\hline Source & Sum of squares & $\mathrm{df}$ & Mean square & $F$ & Significance & Partial eta squared \\
\hline Pre-test & 6.357 & 1 & 6.357 & 0.615 & 0.44 & 0.012 \\
Group & 843.258 & 1 & 843.258 & 81.593 & 0.01 & 0.625 \\
Error & 506.413 & 49 & 10.335 & & & \\
Total & $28,580.000$ & 52 & & & & \\
\hline
\end{tabular}

With pre-test data as covariates, this table shows the analysis of maintaining interactions with others assessment between the two groups. There is a significant increase in this ability among the active group when compared to passive group

with autism have difficulties with direct social engagement; hence, musical activities in the social context provide valuable opportunities for interactions with social partners [18]. The current research work was conducted to study the impact of MT on social skills of children with ASD and to analyze the significance of its effect post MT.

ASD children have difficulties in the process and control of emotions, but they can identify rich emotions embedded in the music as well as a normal child [19]. A study has reported that the speech and auditory cortical areas of ASD children aged from 5 to 22 years were stimulated much better while listening to music compared with the typical developing children [20]. Bonnel et al. showed that pitch processing is heightened in "high-functioning" autism as pitch discrimination and categorization enhances visual performance to the auditory sphere [21]. According to "Enhanced Perceptual Functioning," an autistic person can perform better compared with a normal individual in a range of lowlevel perceptual tasks [22].

ASD children manifest impairment in applying nonverbal behaviors which is needed to regulate interaction and communication. Orff-Schulwerk method can be considered as nonverbal because communications in Orff groups are mediated through songs and chants, leading to the rhythm of speech and body movement and highlighting the nonverbal elements of music. This helps in improving the nonverbal behaviors of ASD children and enhancing their social skills. Our results showed that similar to how people react positively to music exercises, ASD individuals also had their own innate musical processing, perception skills which helped in enhancing the social skills among these children.
This present study showed that Orff method (active group) showed better results compared with the passive group which received only MT, without any further interactions. It was noted that the mildly and moderately affected ASD children from both the groups reacted better to the songs with high pitch and tempo though the severely affected children did not show much reaction. The statistical analysis results also showed that the effectiveness of MT on social skills of children with Orff method in ASD group has been consistent for up to 3 months after the intervention period compared with the only MT passive group. The schools have continued to provide musical therapy to the children due to our positive results.

A limitation of this study was that the participants were selected only from Coimbatore City and that the age of the ASD children ranged from 6 to 12 years old only. This makes it difficult to generalize the effect of MT on all autistic individuals-old and young. Also, the social skill domain was the only aspect studied and not the language and motor skills, which also needs to be evaluated. As MT alone cannot yield the optimal outcomes, occupational therapy and pharmacological therapy, if needed, should be combined to take care of these special group of children.

\section{Conclusion}

Social skill improvement is one among the area for MT intervention as the distinctive aspects of music-based approaches have shown to aid ASD individuals significantly. Different types of MT intervention methods have been established which comprises of improvisational music therapy and neurological music therapy. Extensive

Table 8 Analysis of post-test, follow up phase using dependent $t$ test analysis

\begin{tabular}{|c|c|c|c|c|c|c|c|c|}
\hline \multirow[t]{3}{*}{ Source } & \multicolumn{5}{|c|}{ Paired differences } & \multirow{3}{*}{$\begin{array}{l}T \\
\text { test }\end{array}$} & \multirow[t]{3}{*}{ df } & \multirow{3}{*}{$\begin{array}{l}\text { Significance } \\
\text { (two-tailed) }\end{array}$} \\
\hline & \multirow[t]{2}{*}{$\overline{\text { Mean }}$} & \multirow[t]{2}{*}{ SD } & \multirow{2}{*}{$\begin{array}{l}\text { Standard Error } \\
\text { Mean }\end{array}$} & \multicolumn{2}{|c|}{ 95\% Confidence interval of the difference } & & & \\
\hline & & & & Lower & Upper & & & \\
\hline Social skills & 2.827 & 10.988 & 1.524 & -0.232 & 5.886 & 1.855 & 51 & 0.069 \\
\hline
\end{tabular}

This table shows that there is no significant difference in social skills between the post-test and follow-up 
research reports about MT in ASD shows encouraging results. More studies among various populations, different age groups, different severity levels of ASD, as well as focus on all domains of ASD, such as communication and motor skills are needed in order to accomplish promising results.

\section{Abbreviations}

ANCOVA: Analysis of covariance; ASD: Autism spectrum disorder; CARS: Childhood Autism Rating Scale; MT: Music therapy; RCT: Randomized clinical trials; TSSA: TRIAD special skills assessment

\section{Acknowledgements}

The authors would like to thank Science and Engineering Research Board (SERB) for providing financial support to complete this work. We also thank Bharathiar University for providing support to complete this manuscript. We also thank all the participants and their guardians for their support and cooperation

\section{Funding}

The authors would like to thank the Science and Engineering Research Board (SERB) (ECR/2016/001688), Government of India, New Delhi for funding this research.

\section{Availability of data and materials}

All data and relevant materials obtained from this study are available in the manuscript.

\section{Authors' contributions}

Study design and data collection-GB, BV, manuscript writing - GB, AV, final approval—BV. All authors read and approved the final manuscript.

\section{Ethics approval and consent to participate}

Ethical clearance for this study was obtained from two institutes-(1) Karpagam Medical College Hospital on 31.03.2017 and (2) K.G. Hospital and Postgraduate Medical Institute on 07.04.2017. Informed written consent was taken from the guardians of the participants after explaining the details of the research.

\section{Consent for publication}

Not applicable.

\section{Competing interests}

The authors declare that they have no competing interests.

\section{Publisher's Note}

Springer Nature remains neutral with regard to jurisdictional claims in published maps and institutional affiliations.

Received: 2 November 2018 Accepted: 10 June 2019

Published online: 25 June 2019

\section{References}

1. Geetha B, Sukumar C, Dhivyadeepa E, Reddy JK, Balachandar V. Autism in India: a case-control study to understand the association between socioeconomic and environmental risk factors. Acta Neurol Belg. 2018:1-9. https://doi.org/10.1007/s13760-018-01057-4.

2. Gresham FM. Social skills training: should we raze, remodel, or rebuild? Behav Disord. 1998;24(1):19-25.

3. Venugopal A, Chandran M, Eruppakotte N, Kizhakkillach S, Breezevilla SC, Vellingiri B. Monogenic diseases in India. Mutat Res. 2018;776:23-31.

4. Yinger OS, Gooding L. Music therapy and music medicine for children and adolescents. Child Adolesc Psychiatr Clin N Am. 2014;23(3):535-53.

5. Brown LS, Jellison JA. Music research with children and youth with disabilities and typically developing peers: a systematic review. J Music Ther. 2012:49(3):335-64.

6. Gold C, Wigram T, Elefant C. Music therapy for autistic spectrum disorder. Cochrane Database Syst Rev. 2006;2. https://doi.org/10.1002/14651858. CD004381.pub2
7. Geretsegger M, Elefant C, Mössler KA, Gold C. Music therapy for people with autism spectrum disorder. Cochrane Database Syst Rev. 2014;6(6):CD004381.

8. Ghasemtabar SN, Hosseini M, Fayyaz I, Arab S, Naghashian H, Poudineh Z. Music therapy: an effective approach in improving social skills of children with autism. Adv Biomed Res. 2015;4:157.

9. Stevens E, Clark F. Music therapy in the treatment of autistic children. J Music Ther. 1969:6(4):98-104.

10. Ruttenberg BA, Dratman ML, Fraknoi J, Wenar C. An instrument for evaluating autistic children. J Am Acad Child Psychiatry. 1966;5(3):453-78.

11. Thaut MH. Measuring musical responsiveness in autistic children: a comparative analysis of improvised musical tone sequences of autistic, normal, and mentally retarded individuals. J Autism Dev Disord. 1988;18(4): $561-71$

12. Wimpory D, Chadwick P, Nash S. Brief report: musical interaction therapy for children with autism: an evaluative case study with two-year follow-up. J Autism Dev Disord. 1995;25(5):541-52

13. Katagiri J. The effect of background music and song texts on the emotional understanding of children with autism. J Music Ther. 2009;46(1):15-31.

14. Walworth DD. The use of music therapy within the SCERTS model for children with autism spectrum disorder. J Music Ther. 2007:44(1):2-22.

15. Stephens CE. Spontaneous imitation by children with autism during a repetitive musical play routine. Autism. 2008:12(6):645-71.

16. Kern $\mathrm{P}$, Wolery $\mathrm{M}$, Aldridge $\mathrm{D}$. Use of songs to promote independence in morning greeting routines for young children with autism. J Autism Dev Disord. 2007;37(7):1264-71

17. Kern $\mathrm{P}$, Aldridge $\mathrm{D}$. Using embedded music therapy interventions to support outdoor play of young children with autism in an inclusive community-based child care program. J Music Ther. 2006;43(4):270-94.

18. Bhat AN, Srinivasan S. A review of "music and movement" therapies for children with autism: embodied interventions for multisystem development. Front Integr Neurosci. 2013;7:22.

19. Heaton $P$, Hermelin B, Pring L. Can children with autistic spectrum disorders perceive affect in music? An experimental investigation. Psychol Med. 1999; 29(6): $1405-10$

20. Lai G, Pantazatos SP, Schneider H, Hirsch J. Neural systems for speech and song in autism. Brain. 2012;135(3):961-75.

21. Bonnel A, Mottron L, Peretz I, Trudel M, Gallun E, Bonnel A-M. Enhanced pitch sensitivity in individuals with autism: a signal detection analysis. J Cogn Neurosci. 2003;15(2):226-35.

22. Mottron L, Dawson M, Soulieres I, Hubert B, Burack J. Enhanced perceptual functioning in autism: an update, and eight principles of autistic perception. Autism Dev Disord. 2006;36(1):27-43.

\section{Submit your manuscript to a SpringerOpen ${ }^{\circ}$ journal and benefit from:}

- Convenient online submission

- Rigorous peer review

- Open access: articles freely available online

High visibility within the field

- Retaining the copyright to your article

Submit your next manuscript at $\boldsymbol{\nabla}$ springeropen.com 